\title{
Special and differential treatment in the WTO: framing differential treatment to achieve (real) development
}

\author{
Aniekan Ukpe
Law Group, Wageningen University and Research, Wageningen,
The Netherlands, and \\ Aniekan Ukpe
Law Group, Wageningen University and Research, Wageningen,
The Netherlands, and \\ Aniekan Ukpe
Law Group, Wageningen University and Research, Wageningen,
The Netherlands, and \\ Sangeeta Khorana
Department of Accounting, Finance and Economics, \\ Sangeeta Khorana
Department of Accounting, Finance and Economics, \\ Bournemouth University, Poole, UK
}

Bournemouth Uhiversity, Poole, UK

\begin{abstract}
Purpose - Special and differential treatment (SDT) in the World Trade Organisation (WTO) has failed to integrate developing countries into the international trading system, as contemplated by the WTO Agreement, itself. This paper aims to interrogate the current application of SDT by WTO members as the possible undermining factor for SDT not delivering on its objective.

Design/methodology/approach - The research uses a qualitative legal methodology. This study conducts desk analysis of primary legal materials and existing literature to assess current reflections of SDT and draw lessons for reforms in the WTO.

Findings - From interrogating current SDT practice in the WTO and a comparative analysis with a similar differential treatment under the Montreal Protocol, this paper finds that indeed, the problem lies in the current approach to SDT application in the WTO. This study finds that the existing absence of eligibility criteria for determining access to SDT by countries is the core reason for the abuse and sub-optimal outcome from its application.

Originality/value - While making a case for a rules-based approach to differentiation in the WTO, this paper proposes a unique methodology for differentiating between developing countries for SDT, including the use of a composite indicator to ensure that indicators that are used sufficiently reflect their heterogeneous needs. Drawing inspiration from Gonzalez et al. (2011a), this study introduces an adaptation for selecting a threshold for graduation. Specifically, the proposal on the value of the standard deviation of countries from the weighted mean of the composite indicator as the threshold for graduating countries from SDT is novel.
\end{abstract}

Keywords Developing countries, WTO, Special and differential treatment

Paper type Research paper

\section{Introduction}

The use of special and differential treatment (SDT) in the World Trade Organisation (WTO) has attracted a great deal of academic attention and it is widely debated whether SDT is a

(C) Aniekan Ukpe and Sangeeta Khorana. Published by Emerald Publishing Limited. This article is published under the Creative Commons Attribution (CC BY 4.0) licence. Anyone may reproduce, distribute, translate and create derivative works of this article (for both commercial and noncommercial purposes), subject to full attribution to the original publication and authors. The full terms of this licence may be seen at http://creativecommons.org/licences/by/4.0/legalcode 
JITLP 20,2

development tool (aimed at addressing the problems of developing countries) or a trade tool (to support the integration of developing countries into the trading system) (Lee, 2016; Page, 2004; Conconi and Perroni, 2015; Hoekman, 2005; Ornelas, 2016; Surono and Hidayati, 2019). Furthermore, the accessibility of SDT by members at different levels of development is long overdue for reconsideration. Our paper aims to critique the current framework for SDT, review extant literature and propose an alternative framework for determining eligibility for and content of SDT.

Traditionally, SDT was designed to help developing countries to develop their economies through exports and to enable them to pursue policy options that they considered appropriate for development [1] (Kleen and Page, 2005; Ornelas, 2016). Discussions have, however, continued to rage in the academic and policy domains on how best to streamline SDT to align with developing countries' national economic development strategies and invariably, better respond to their development needs (Prowse, 2002; Hoekman et al., 2004; Hoekman et al., 2003; Cottier, 2006; Keck and Low, 2004). The focus has since changed and the justification for SDT is now to support developing countries to overcome problems faced in implementing trade commitments (Page, 2004; Keck and Low, 2004; Imboden, 2017). Furthermore, there is growing dissent against the "one size fits all" principle of SDT, including calls to introduce a higher level of differentiation between developing countries (Hoekman et al., 2003; Finger, 1991). The objection has been underscored by former US Trade Representative, Robert Zoellick and former EU Commissioner for External Trade, Peter Mandelson [2]. They both expressed concerns on the need to ensure the "right degree of differentiation" for a robust SDT regime that addresses the needs of developing countries in the WTO. The Trump administration has explicitly sought changes to the flexibilities provided and has claimed that SDT reflects an outdated dichotomy between developed and developing countries, such that the need for countries to "self-declare" their developing country status amplifies the problem (USG, 2019; WTO, 2019a). While there is a lack of support for SDT as a growth-promoting strategy, there is also an emerging need for further research that explicitly tackles the challenges that it presents. Past WTO Rounds, inextricably linked SDT negotiations to introducing differentiation between developing countries, suggesting that an ambitious SDT regime can be achieved as a trade-off for differentiation amongst beneficiaries. While developing countries on their part made no pretext about the rejection of the principle of differentiation [3], SDT continues to be couched in a vague and faded language without specific objectives and measures (Paugam and Novel, 2005). In effect, SDT talks at the multilateral level have remained deadlocked for over two decades [4]. Within the current context, an important question is whether the rules of the multilateral trading system, as currently framed, sufficiently promote development. If not, how best can the current rules be redesigned to achieve the development objectives?

The paper discusses the current SDT framework at the WTO, examines options and suggests how the WTO could promote development by allowing targeted SDT. In particular, the paper examines whether the existing rules-based approach to differentiation in the WTO can serve as a blueprint for an effective and developmentoriented application of SDT. The structure of the paper is as follows: Section 2 reviews underlying factors that determine SDT eligibility at the multilateral level. Section 3 outlines the case for differentiation in the WTO. Section 4 reviews alternative theoretical options for differentiation and advances to present reform proposals. Section 5 offers conclusions. 


\section{Issues with special and differential treatment}

\subsection{Application of rules}

The preamble of the WTO underscores the economic development of developing countries as a major objective and encourages "positive efforts" by developed country members to actualise it [5]. WTO agreements also reflect the underlying intent of SDT and policies to support the development and integration of developing countries into the global trading system. SDT provisions specifically aim to enhance trading opportunities for developing countries, protect their interests and allow flexibility in taking on new trade obligations, as well as in the use of trade policy instruments (Lee, 2016). It has been opined by experts that other than merely reflecting developmental aspirations, WTO disciplines generally fall short of advancing the interests of developing countries in real terms. For instance, while export subsidies (an important policy tool for many developing countries) are prohibited by WTO rules, farm support to agricultural produce by developed countries is not (Lee, 2016, p. 451). Historically, countries such as the UK and the USA permitted the use of special treatment by countries to enable the development of specific sectors. Both countries allowed the use of export subsidies in the $18^{\text {th }}$ and $19^{\text {th }}$ centuries by their former colonies to develop their textile industry and the rail sector, respectively, but developing countries are denied this under the current SDT framework (Lee, 2016, p. 451; Chang, 2002). Similarly, trade-related investment measures (TRIMs) such as local content requirements, (also, an important policy tool used by many developing countries to increase local inputs in production processes) are prohibited by WTO rules [6]. Evidence also suggests that several developed WTO member countries have used similar investment measures and protectionist policies such as import substitution and high tariffs, to support their industrial development. (Shafaeddin, 1998).

Given that the benefits of preferential schemes are being increasingly eroded, developing countries have also questioned the economic value of traditional SDT. Lower tariffs, which are a result of WTO negotiations, have resulted in the loss of benefits granted to developing countries and LDCs (Francois, 2006). This has exposed the LDCs in particular, to competition from highly efficient developed country competitors and also provided them with far less competitive market access conditions for their key exports. On the part of developed countries, there has been a clear change in attitude to SDT. While developed countries continue to recognise the specific needs of LDCs, they are less willing to accord SDT to emerging economies, which have become major trading powers over time [7]. Indeed, the increasing share of developing countries such as Mexico and Turkey, in global trade questions the basis and legitimacy of SDT. This is given that exports from developing countries represent nearly $50 \%$ of all global exports, with the largest 15 developing countries accounting for about three-fourths of those exports (UNCTAD, 2019). All these issues underscore the rationale to seek to secure convergence amongst WTO members on acceptable criteria for reviewing the current SDT framework.

\subsection{The definition of "developing country"}

The present categorisation of developing countries at the WTO applies to a wide range of countries that, in reality, are disparate in terms of their level of development. The category of LDCs, created by the UN in 1971 and adopted by the WTO, is the only formal categorisation reflecting the least developed amongst the developing countries [8]. Under the Enabling Clause deeper flexibilities such as longer transition periods to implement disciplines and deeper preferences in the context of preferential trade programmes, are accorded to the LDCs [9].

The concept of "developing countries" can be traced to the provision of GATT where Article XVIII of GATT 1947 gave developing countries the right to protect infant industries 
JITLP 20,2

and use trade restrictions for balance-of-payments purposes. Articles XXXVI, XXXVII and XXXVIII of GATT 1994 subsequently recognised the special needs of developing countries and exempted them from making reciprocal concessions during trade negotiations. Article XVIII(1) provides that:

$[t]$ he contracting parties recognise that the attainment of the objectives of this Agreement will be facilitated by the progressive development of their economies, particularly of those contracting parties the economies of which can only support low standards of living and are in the early stages of development.

Paragraph 4(a) of the Article explains its purpose as being to allow a contracting party, whose economy "can only support low standards of living and is in the early stages of development", to be free to deviate temporarily from the provisions of the other Articles of the GATT under prior defined circumstances. This is, perhaps, the closest that the GATT/ WTO system has come to defining "developing countries" (Cui, 2008, p. 133). Reading Paragraphs 1 and 4(a) of Article XVIII together, Cui, 2008 highlights the two criteria to support the identification of a developing country. The first is "low standard of living" and the second is "in the early stage of development". Cue, however, raises questions on how low the standards of living should be and at what stage of development can a country qualify to be in an "early stage of development" (Cui, 2008, p. 134). Annex I to the GATT provides an insight in respect of both criteria. By "low standards of living", it urges members to consider the normal position of that economy rather than the exceptional circumstances such as those that may result from the temporary existence of exceptionally favourable conditions. In the case of "early stage of development", Annex I explains that the phrase is not meant to apply only to contracting parties that have just started on the process of economic development, but applies to contracting parties whose economies are undergoing industrialisation to reduce their dependence on primary products' production [10].

The explanation in Annex I on how to identify a developing country, however, falls short of establishing any objective criteria to guide an attempt to draw up a list of "developing countries". The language used in attempting a definition lacks any legal precision and is, at best, a guide in which the phrases of "low standards of living" and "in the early stage of development" should be interpreted. Citing Ceylon-Article XVIII Applications [11], Cui (2008) illustrates the arbitrariness that underlies such criteria in defining "developing countries". In this case, Ceylon had applied to the GATT Working Party under Article XVIII to seek exemption for a period of 10 years to impose quantitative restrictions on the importation of specified petroleum products if at any time this should prove necessary to ensure the development and operation of the domestic, petroleum refinery. In examining Ceylon's application, the GATT Panel had to first consider whether Ceylon was eligible under paragraph 4(a) of Article XVIII. Going by the criteria of "low standards of living", the Panel found that the gross national product (GNP) per capita for Ceylon in 1955 was US\$128. This was higher than the GNP per capita of countries such as Burma and India, but lower than that of Greece, Cuba and the Dominican Republic and very substantially lower than the GNP per capita of industrialised countries in Western Europe. To examine the criteria and decide whether Ceylon was "in the early stage of development", the Panel based its consideration on the share of manufacturing, mining and construction in the country's GNP. This share (including mining, a primary industry) was found to be about $10 \%$, a figure lower than that of Burma and Greece and substantially lower than that of developed industrial countries [12]. Cui (2008) considers the Panel's preference for GNP per capita over the gross domestic product (GDP) per capita or other national income indicators, in the determination of both "low standards of living" and "in the early stage of development" as arbitrary. This is given 
that the Panel provided no reasons for the preference (Cui, 2008, p. 135). Cui (2008, p. 135) made the same point in respect to the Panel's inclusion of mining in the calculation of the share of certain industries relative to the GNP. He opines that albeit, the Panel's choice was seemingly arbitrary it was justified because there was no provision in GATT Article XVIII to govern such issues. Nevertheless, the use of socioeconomic indicators to categorise countries by their level of economic development is widespread. The World Bank and the Organisation of Economic and Cooperation Development (OECD) use economic criteria such as GNP per capita; vulnerability index; social criteria such as human development indexes and institutional criteria such as governance and freedom index. However, these indicators generally fail to specifically address trade-related concerns of developing countries. Also, the very fact that they seek to measure broad development issues for which the WTO has no mandate makes them unsuited for the WTO (Paugam and Novel, 2005, p. 11).

\subsection{Self-designation for qualification}

Self-designation is a means for developing countries to qualify for SDT at the WTO. Rolland (2012) acknowledges that WTO members self-designate in a bid to secure the benefits of various SDT provisions (Rolland, 2012). She, however, notes that the claim is not consistent with reality. In reality, while individual countries are at liberty to self-designate, such selfdesignation is subject to scrutiny by other WTO members (Rolland, 2012; Verdirame, 1996). Any member that challenges a claim by another to developing country status bears the burden of disproving the claim as opposed to any expectation on the claimant to prove its claim (Cui, 2008, p. 139). Nevertheless, accepted practice suggests that the self-designating country/claimant may bear the burden of demonstrating that it meets the requirements to benefit from the SDT [13].

Implicit in the practice of self-designation is that a country at a different level of development can claim the status of a developing country and, once claimed, that country is entitled to SDT, irrespective of its capacity or level of development. The problem with such an across-the-board approach is that it fails to respond to actual development needs and in some cases even creates unfair competition between developing countries for trade opportunities. For instance, a small country, like Gambia with a GDP per capita as low as US\$528.79 in 2014 has to compete with a large developing country like Mexico with a GDP per capita of almost US $\$ 10,000$ in 2015. Of course, Gambia is already prejudiced from the onset, in terms of the level of its resources and capacity and does not stand a chance to favourably compete with Mexico. This underscores the point that the WTO must ensure a level playing field, not just between developed and developing countries, but also between developing countries.

\section{The legal case for "differentiation" between beneficiaries}

Rolland (2012) notes that the continued absence of specific criteria for determining whether a country qualifies as "developing" or not, has seen countries with significant differences, e.g. in size, population, economic and trade capacities, geographical and political conditions, which include Chile, Brazil, India and Korea, being treated as developing countries in WTO jurisprudence (Rolland, 2012, p. 80). Such factual discrepancy between legal uniformity and economic diversity underscores the need to achieve a balance in the application of trade rules for countries at the WTO. In this context, the principle of differentiation is rooted in the need to treat similarly situated developing countries similarly [14]. Differentiation was introduced to reduce the political and economic conundrum associated with claims for preferences by a wide diversity of developing countries. Preferences could, however, still be 
JITLP

20,2

claimed by developing countries on a needs-basis and without undermining the gains from reciprocal concessions, to developing countries as a whole (Rolland, 2012, p. 159).

The use of "special" and "differential" at the WTO supports the view that differential treatment is intrinsic to the SDT framework. Given developing countries are at different levels of development and with varying needs a "one size fits all" approach cannot address the divergent needs of this group of countries. It is, thus, not surprising that the WTO Appellate Body, in the EC-Tariff Preference case [15], held that "the needs of developing countries vary over time" and that differentiation between countries is allowed to respond to their different development, financial and trade needs [16]. The Appellate Body not only gave judicial backing to the principle of differentiation but also set out the conditions authorising the application of differentiation between developing countries in preferential trade regimes. The Appellate Body ruled that in granting differential tariff treatment, preference-granting countries are required by virtue of the term "non-discriminatory", to ensure that identical treatment is available to all similarly situated beneficiaries of a generalised scheme of preferences (GSP). In other words, all GSP beneficiaries with the same "development, financial and trade needs" are entitled to the same treatment that a particular GSP scheme offers in response to such needs. The term "non-discriminatory" does not prohibit developed countries from granting different tariffs to products originating in different GSP beneficiaries, provided that such differential tariff treatment meets the remaining conditions in the Enabling Clause [17]. The "similarly situated" approach advocated by the Appellate Body provides legal support to initiatives that propose differentiating between developing countries for purposes of according SDT only to those that actually need it.

Drawing from the WTO panel in the US-Copyright case [18], the word "special" connotes "having an individual or limited application or purpose"[19]. Within the context of SDT, it can be implied to suggests that for a treatment to be considered special, it must apply to a particular country or case based on objective facts or conditions that are peculiar to that individual or case. In other words, a treatment that is made available to cases simply on the basis that they fall within a broad and subjectively defined category such as the category of developing countries in the WTO, cannot be said to be special. From this, it would appear that the distinction between differential treatment and "special" treatment lies in the focus of each term [20]. While the focus of the former is on different categories, that is, by allowing special treatment to distinguish between one category and another, the latter focusses on the peculiarities of an individual or a case. Where "categories" exist, special treatment will not simply apply broadly to all members of a category. It looks into the "category" to identify meritorious and deserving individual cases based on objective facts or conditions. So, while it may be the case that all countries of a particular category are categorised based on a common (and often broad) differentiating factor, it cannot be the case that all WTO members of such particular category are entitled to the same special treatment simply on the basis that they are included in the same category. Nevertheless, this can indeed be the case if all countries in a given category exhibit the same unique characteristics that warrant the same special treatment.

Important differences exist between "special" and "differential" treatment, despite being used relatedly at the WTO. This precipitates the debate on the need to link the two words "special" and "differential" - in the WTO. Paugam and Novel (2005, p. 4) opine that a scrutiny of the rationales for countries' resort to the usage of the Enabling Clause offers some insight into the differences. On the one hand, the Enabling Clause exclusively uses the term "special" in reference to the sub-category of least developing countries, particularly so, in urging regard for their "special economic difficulties and the particular development, 
financial and trade needs". On the other hand, the authors report that the notion of "differential" and "more favourable" treatment is used in reference to a broader category of "developing country" (Paugam and Novel, 2005, p. 4). Thus, it can be reasonably deduced that the Enabling Clause accords differential treatment to only developing countries, including the sub-set of LDCs as distinct from treatment which is generally available to all WTO members. Given some peculiar features, circumstances or needs of some countries within the category of developing countries, i.e. LDCs, the Enabling Clause allows for further differentiation to offer "special treatment" to this sub-category of developing countries in response to their peculiar features, circumstances or needs [21]. "Special", is used to distinguish the treatment available exclusively for LDCs from the treatment that is generally available to the broader group of developing countries qualifying for SDT (Rolland, 2012, p. 80). Thus, the specific features, circumstances or needs of LDCs, are the basis for according them special treatment and not simply the basis that they are developing countries. If at all, the latter only prequalifies them.

Paragraph 7 of the Enabling Clause clearly affirms the intention of WTO members to treat developing countries differently when it comes to holding them to their trade obligations. Such is to be directly linked with a demonstrable and improving capacity of these countries to participate in international trade. Paragraph 9 of the Clause further underscores the principle of graduation by which developing countries are expected to take up reciprocal trade commitments as their capacities improve. It reflects the idea of graduating developing countries from SDT based on some objective criteria. In other words, it allows for differential treatment of developing countries on the basis of such objective criteria. This is without prejudice to the fact that the Enabling Clause defined no such objective criteria.

\section{Approaches to differentiation and proposals for reform}

The ability to develop countries to implement and benefit from the implementation of WTO rules and disciplines varies, depending on factors such as their institutional capacity, income, size and level of development. This underscores the need for differentiation between countries to appropriately determine which rules should apply to which countries at any point in time. This raises the following questions: - which developing countries can benefit from implementing a specific rule such that the benefits exceed implementation costs? Which country requires SDT before it is able to implement such rules? The rationale for these questions is that some developing countries do not have the capacity to implement the rules even if these were beneficial. They would require some support to be able to implement the rules and reap associated benefits. Differentiation, thus, becomes important to sort developing countries effectively to achieve development. The WTO specifically recognises and differentiates between developing countries. Indeed, efforts to differentiate between developing countries for the purpose of determining SDT eligibility are consistent with the letter and spirit of WTO law [22]. It remains, however, that "objective criteria”, which should serve as the basis for such differentiation across WTO agreements are yet to be clearly articulated. This section reviews existing approaches to differentiation and suggests reform of the current SDT framework [23].

\subsection{Country-based approach}

Country-based approaches tend to group countries at a similar development level and context for the purpose of SDT application. The grouping could either be based on geographical or socio-economic criteria. The rationale for the geographical approach is that huge diversities exist in respect of the development and trade needs of countries in the same 
JITLP

20,2

90

regional grouping. For instance, the development situation and trade needs of Sub-Saharan countries such as the Gambia, South Africa and Kenya, depicts huge variance that would require differential treatment to achieve the objective of SDT in the WTO. Albeit, we earlier questioned the propriety of using socioeconomic indicators to categorise countries at the WTO, using them to determine countries' eligibility for SDT holds huge prospects for successfully reforming SDT in the WTO.

Hoekman et al., 2004 and Paugam and Novel, 2005 suggest what is a hybrid (of the country-based approach and a rules-based approach) which identifies an "LDC+" group that would be required to comply with the "core" WTO principles of non-discrimination, prohibition of quantitative restrictions, tariffs binding and transparency. They argue that some WTO disciplines may generate significant implementation costs and prove unsuited to particular developing countries' circumstances, especially for low-income countries (Paugam and Novel, 2005, p. 14). Thus, it is important to ensure that countries have the scale needed for benefits to exceed implementation costs before implementing a rule in issue. This approach would require redefining the existing three-fold country classification at the WTO. Hoekman et al., 2004 suggest that stricter economic-based criteria would be required to regroup countries along the lines of income levels and institutional capacities such that only low-income and small economies should qualify for SDT (Hoekman et al., 2004, p. 494).

\subsection{Rules-based approach}

The rules-based approach aims to define objective criteria for SDT eligibility on an agreement-by-agreement basis (Paugam and Novel, 2005, p. 12). Stevens (2002) suggests that such an approach is based on the premise that eligible countries must share a set of differences that are directly related to the rules for which SDT is proposed. Hoekman et al. (2003) propose that the rules-based approach involves country-based criteria that are applied on an agreement-by-agreement basis to determine whether (when) agreements should be implemented. Essentially, countries that exhibit similar "differences" in respect to a particular rule for which SDT is required, must be accorded such SDT. However, whether the same group of countries receives SDT in respect of another rule is an entirely independent consideration.

\section{3 "Differentiated differentiation" approach}

While there is a lack of consensus on appropriate criteria for country categorisation at the WTO [24], it is unarguable that more differentiation between countries is vital if SDT is to become a useful tool to address the special concerns of developing countries [25]. This paper advocates defining the eligibility criteria for allowing countries access to the SDT on an agreement-by-agreement basis [26]. While this may attract academic critique, the rationale for this approach is based on the fact that SDT should be geared towards supporting countries to improve their rule implementation capacities. Under this approach, graduation from SDT is not horizontal, given that a country may graduate from SDT for a particular WTO agreement, but may remain eligible for SDT under another agreement.

The suggestion that "particular concerns" "should be taken into consideration, as appropriate, in the course of the Agriculture and NAMA negotiations" is an indication that special attention could be given to the concerns of developing countries (including capacity constraints) as they undertake increasing WTO rule obligations [27]. The WTO, thus, already permits differentiated SDT according to a country's level of development. This could be extended across all agreements. The success of the proposed endeavour, however, lies in defining the criteria for SDT eligibility on an agreement-by-agreement basis rather 
than an across-the-board approach (Hoekman et al., 2003; Keck and Low, 2004; and Stevens, 2002).

While acknowledging that additional resources and efforts would be required to apply this differentiated approach, the advantage of ensuring that SDT responds to specific [traderelated] needs of countries, particularly, as attention is given to the economic costs and benefits of implementation of WTO rules makes it worth the while (Hoekman et al., 2004). The downside to this approach lies mainly in the fact that it requires regular implementation audits, which may likely boil down to an assessment of each beneficiary country's differential treatment implementation of each relevant agreement. Furthermore, the complexities involved in defining objective criteria and the basis for differentiation is another tricky area. Besides, there is no guarantee that the results of implementation audits, i.e. the costs and benefits of implementation, will be acceptable to all WTO members. Finally, the volatility and multistakeholder process that may be required to determine objective criteria acceptable to all WTO members may not only make negotiations more complex but also expose the WTO system to cross-conditionality arising from other international development/financial institutions (Hoekman et al., 2004).

Despite the challenges listed above, the proposed framework is consistent as it provides a transparent analytical approach for a reformed SDT framework, particularly in terms of measuring the economic development needs against the legal provisions. It is most consistent with the "one size does not fit all" approach and ensures that only those countries that justifiably need SDT the most, get it.

\subsection{Implementation proposal for differentiated differentiation}

"Differentiated differentiation" as an implicit threshold approach to differentiation is amenable to the principle of graduation which identifies which countries should be allowed derogation from a particular WTO rule at any given time (Cottier, 2006; Gonzalez et al., 2011a). The rationale for "differentiated differentiation" is that SDT should be geared towards supporting countries to improve their rule implementation capacities rather than provide them with a permanent exemption. Accordingly, the assumption of trade treaty obligations by developing countries should be determined their rule implementation capacity at any given time. To operationalise such modulation of commitments, firstly, determine what constraints developing countries are likely to face in implementing a particular rule [28]. Secondly, identify, based on some analytical criteria, the countries that suffer from these constraints, and hence, lack the capacity to implement the rule. Targeted SDT, including derogation from discipline, could then be offered to such countries to overcome the constraint(s). The objective here is to ensure that SDT is targeted at only those countries that justifiably need it the most. This approach requires that rule implementation is made contingent on a country overcoming a set of identified constraints. That is, the modulation of commitments only kicks in when identified constraints have been overcome. Impliedly, countries that fall below a preferred threshold would be entitled to SDT while those above the threshold would not be eligible for SDT. Adopting a new evidence-based, case-by-case approach to SDT could ensure both that the concerns of the poorest countries are addressed and that advanced developing countries carry their weight in the organisation.

To operationalise a threshold approach to derogation from legal discipline, the use of analytical criteria to identify constraints that countries face as a result of or in the process of rule implementation is central. Gonzalez et al. (2011a, p. 17) note the possibility of a mismatch between the analytical criteria used and actual constraints identified. This acknowledges the fact that the analytical criteria will at best be a proxy for a given 
JITLP 20,2

constraint. Nonetheless, identifying and using a combined set of indicators to identify possible constraints could be less problematic. A composite indicator will better reflect such constraints vis-à-vis the varied needs of countries.

\subsection{Designing a composite indicator approach}

A composite indicator approach is proposed to combine indicators into a composite measure. The composite indicator encapsulates individual indicators, each of which has been pre-ranked according to a weighted structure. In practical terms, this requires firstly, identifying the constraints and proposing appropriate indicators (with weights attached to each) to capture these constraints. Secondly, ranking countries by indicators. Third, taking the average ranking unit (mean) and applying the sets of weights to create a composite indicator. The weights should be an outcome of a negotiated process that takes countries' performance of global trade into consideration. Fourth, determine the relative standing of countries in terms of constraints faced, by the average ranking score of each constraint in relation to the corresponding indicator. This will allow the WTO to draw up a list of developing countries that reflects their heterogeneous needs.

Determining the threshold for graduating countries (on the list of countries) for derogation from a particular discipline is important. In this regard, finding the variance of the average ranking score for each country per indicator of a constraint is required. The second is determining the standard deviation from the weighted mean of the composite indicator. Selecting the value of the standard deviation as our threshold can objectively determine which countries should be allowed derogation from rule implementation and which countries should not be allowed such flexibility. Specifically, only countries that fall below the selected threshold should be allowed such derogation.

\subsection{Procedural reform: a case for improved monitoring of technical assistance delivery}

The question with differentiated differentiation approach remains whether special provisions, for example, that, allow a longer transition period for developing countries to apply international trade obligations could become more effective? Differentiated differentiation will require successful implementation of the WTO agreements and rationalisation of institutional and human resources, policy adaptation and improved coordination with relevant stakeholders to facilitate their participation at the WTO (Prowse, 2002). In practical terms, this would require setting up a multi-stakeholder structure to coordinate the implementation of such agreements; developing agreement-specific strategies and action plans to achieve the goals of each agreement; and putting an appropriate regulatory and legislative framework in place to support reforms aimed at achieving the objective of any particular agreement. For several developing countries and LDCs, the financial and technical resources to initiate and sustain such broad reform are lacking. Technical assistance provisions through the WTO obligate developed countries and the Secretariat to provide technical assistance to help developing countries take full advantage of the multilateral trading system [29]. However, the vagueness of such provisions (in terms of form and purpose) and the non-binding nature of the obligations have generated concerns about their operability.

China's successful compliance with Ozone Depleting Substances (ODS) reduction target under the Montreal protocol [30] offers some insight into how countries could leverage targeted assistance during transition periods, in particular, to comply with their trade obligations [31]. China's case suggests that financial or technical assistance must be linked to a country's compliance with the procedural requirements of an agreement and continuous improvement of its implementation strategies as far as complying with obligations under 
that agreement is concerned. For instance, this could see a developing country receive financial or technical assistance to review its local laws towards complying with its WTO obligations, provided it prior complies with its national/constitutional requirements to adopt WTO agreements [32].

\subsection{Monitoring and review}

To further ensure SDT accountability and effectiveness, a mechanism to monitor and report progress on rule implementation during a transition period could prove invaluable. The July 2004 Package [33] refers to "monitoring and surveillance" in the context of agriculture and suggests only "enhancing" the existing system of notifications [34]. However, the fact that the significant contributions of SDT provisions are spread more across specific WTO agreements than in the general provisions, suggests that integrating any monitoring mechanism(s) into substantive agreements may be a most effective approach. Underscoring the importance of reporting requirements in promoting accountability and effectiveness of treaty obligations, Rolland, 2012 summarises that it could be useful to monitor and improve compliance with obligations; gather the information that may be used for reforming a particular rule or agreement; and, assist in the design and delivery of effective capacitybuilding support to deserving beneficiaries (Rolland, 2012, p. 128). Such a mechanism will be useful in providing early warning signals if a developing country is not on course to meet the SDT objective. Any problem can be timely identified. If such a developing country requires on-going assistance to be redirected or modified, that is done in time to address the problem. This approach will incentivise developing countries to draw motivation from knowing that continuous technical assistance is linked to meeting certain thresholds in their progress towards complying with trade treaty obligations. A mandatory requirement for all SDT beneficiaries to self-report progress as part of a peer review process should also be put in place for the beneficiaries of technical assistance.

\section{Conclusion and the way forward}

Globalisation has altered the pattern of world trade and a few developing countries have progressed from being traditional goods exporters to becoming partners in preferential trade agreements. While the changing pattern of trade has favoured several countries, it has been criticised as limiting the economic freedom of developing countries, in that it prevents them from accessing markets in the rest of the world to support their varied development needs (Verter, 2017). Sen (1999) opined that a major failing of the current SDT approach has been its usage as the basis for exempting developing countries from WTO obligations instead of helping these countries comply with WTO obligations to support full integration into the global trading system. There is ample evidence to suggest that the gains from SDT have been limited and benefits are not being harnessed by developing countries and LDCs, hence, the need to rethink the current SDT framework at the WTO. SDT revision has been in the limelight lately at the WTO with the US' proposal for a strict definition of a "developing country" by WTO rules [35], the EU's proposal for asymmetry in rule obligations amongst developing countries [36], Norway's call for a "constructive conversation [...] about the development dimension"[37], and Canada's call for a balance between reciprocity and flexibility and more differentiation between developing countries [38].

At present, SDT in the WTO is undefined and self-declared. As the debate on SDT has revealed, there is a lack of agreement on what SDT should entail, where it is appropriate and what its purpose should be in the multilateral trading system. Our paper argues that the WTO's approach to SDT must be framed through the lens of "what development means". It is partly for this reason that considering the level or stage of a country's development would 
JITLP

20,2

94

help determine the level and type of SDT required to help it achieve sustainable development. We advocate "differentiated differentiation" for the application of SDT and also make a case for defining SDT eligibility criteria on an agreement-by-agreement basis. "Differentiated differentiation" envisages that SDT is geared towards supporting countries to improve their rule implementation capacity rather than provide them with a permanent exemption. Hence, whether a developing country is allowed to derogate from a particular rule is dependent on its capacity to implement the rule at a given time. In practical terms, we would first need to determine what constraints developing countries are likely to face in implementing that particular rule. Secondly, we would have to identify, based on some analytical criteria, the countries that suffer from these constraints, and hence, lack the capacity to implement the rule. To ensure that selected analytical criteria sufficiently reflect the heterogeneity of possible constraints, we propose a combined set of indicators that will serve to identify such constraints. Targeted SDT, including derogation from discipline, could then be offered to the deserving country to overcome the identified constraint(s). This approach not only puts an end to the long-drawn debate on country re-categorisation in the WTO but also ensures that only those countries that justifiably need SDT the most get it.

To avoid a situation where the SDT framework as proposed, is used as an eternal crutch, the paper advocates for graduating SDT beneficiaries based on a threshold determined by the value of the standard deviation from the weighted mean of the composite indicator. Selecting the value of the standard deviation as our threshold can objectively determine which countries should be allowed derogation from rule implementation and which countries should not be allowed such flexibility. Specifically, only countries that fall below the selected threshold should be allowed such derogation.

Developing countries need to visualise SDT for what it is - a trade tool to promote development. To ensure that SDT advances the development and does not impede it, a broader understanding of the meaning of development must be taken and reflected in the design of an alternative approach to SDT. Consistent with a more comprehensive goal of sustainable development as expressed in the preamble of the WTO Agreement, development should be viewed as an empowering process for individual humans/countries (Bacchus and Manak, 2020; Bacchus, 2004). It is this view that should be the guiding light for efforts to promote development at the WTO. This more expansive view contemplates that trade is a pathway to engaging with the challenges and opportunities of the wider world. Thus, trade becomes a means to promote the broadest fulfilment of both individual and national potential (Bacchus and Manak, 2020). This broader view of what development means must be reflected in SDT design at the WTO. The focus of SDT should, thus, not be on more exclusion but more inclusion. SDT "should enable rather than exempt” (Low et al., 2019).

\section{Notes}

1. WTO (2001), Preparations for the Fourth Session of the Ministerial Conference: Proposal for a Framework Agreement on Special and Differential Treatment, para. 1, WT/GC/W/442, 19 September

2. World Street Journal (2004), "Robert Zoellick's Letter to WTO Member Nations", 11 January, available at https://www.wsj.com/articles/SB107393275634376900 (accessed 7 August 2020); Mandelson, P. (2005), "Doha for Development" Speech to Informal Meeting of EU Development Ministers, Leeds, UK, available at: https://ec.europa.eu/commission/presscorner/detail/en/ SPEECH_05_639 (accessed 8 February 2020).

3. Mexico and South Korea, both developing countries at the WTO and OECD members torpedoed OECD's research initiative on countries' economic calibration. India launched a major WTO 
dispute against "the Drug Arrangements" in the 2001 EU GSP scheme, alleging discriminatory differentiation amongst developing countries.

4. Almost two decades after its launch in 2001, the Doha Round (also known as the Doha Development Agenda) which specifically aimed to advance development interests, including addressing the problems developing countries face in implementing WTO agreements, remains stalled. Details on the Round is available at: https://www.wto.org/english/tratop_e/dda_e/dda_e.htm (accessed 4 May 2020).

5. Preamble to the Marrakesh Agreement Establishing the WTO, available at: https://www.wto. org/english/res_e/publications_e/ai17_e/wto_agree_preamble_jur.pdf (accessed 26 April 2020).

6. The WTO's Agreement on Trade-Related Investment Measures (TRIMs) prohibits any investment measures that may be inconsistent with Articles III (national treatment) and XI (prohibition of quantitative restrictions) of the GATT. See also Lee (2016).

7. https://www.whitehouse.gov/presidential-actions/memorandum-reforming-developing-countrystatus-world-trade-organization/ (accessed 8 March 2020).

8. The criteria for designating a country as an LDC by the UN are low income, weak human assets and high economic vulnerability in addition to the requirement of the country not exceeding the population of 75 million. See https://www.un.org/development/desa/dpad/least-developedcountry-category/ldc-criteria.html (assessed 29 April 2020).

9. Paragraph 2(d) of the Enabling Clause permits deeper differentiation to accord special treatment to the least developed amongst the developing countries in the context of any general or specific measures in favour of developing countries.

10. GATT, Annex I Notes and Supplementary Provisions, Ad Article XVIII.

11. Panel Report, Ceylon-Article XVIII Applications, GATT Doc. L/71 (26 November 1957).

12. Ibid, at para. 4 .

13. Chile Taxes on Alcoholic Beverages case (Arbitration procedure under Article 21.3(c) of the Understanding on Rules and Procedures Governing the Settlement of Disputes), WT/DS87/15 (23 May 2000), para. 18.

14. WTO Appellate Body Report, European Communities-Conditions for the Granting of Tariff

Preferences to Developing Countries, WT/DS246/AB/R (7 April 2004).

15. WTO Appellate Body Report, European Communities-Conditions for the Granting of Tariff

Preferences to Developing Countries, WT/DS246/AB/R (7 April 2004).

16. Ibid, paras. 169 and 173.

17. Ibid, paras. 160-62.

18. Panel Report, United States - Section 110(5) of the US Copyright Act, WT/DS160/R, 15 June 2000.

19. Ibid, para. 6.109 .

20. The usage of the two terms by the Enabling Clause is instructive. The Enabling Clause exclusively uses "special treatment" in reference to distinctive treatment available to the sub-category of LDCs only (in the context of measures available to all developing countries) while "differential and more favourable treatment" is used in reference to treatment available to the broader category of developing country. See paras 1 and 2 of the Enabling Clause. See Paugam and Novel:4, 2005.

21. Paragraph 2(d) of the Enabling Clause.

22. E.g. Article 27(5) and (6) of the WTO Agreement on Subsidies and Countervailing Measures categorises developing countries into four groups for determining which country should be allowed the use of export subsidies. The Agreement on Agriculture provides for Net Food- 
JITLP

20,2

\section{6}

Importing Developing Countries (NFIDC), an entirely new sub-category of food insecure developing countries that require food aid and other financial and technical assistance.

23. For a detailed analysis of these approaches, (Paugam and Novel, 2005; Hoekman et al, 2004 and Hoekman, 2005).

24. WTO (2019b), "The Continued Relevance of Special and Differential Treatment in Favour of Developing Members to Promote Development and Ensure Inclusiveness", Communication from China, India, South Africa and the Bolivarian Republic of Venezuela WT/GC/W/765, WTO, Geneva, 28 February.

25. Recent EU reform proposal recognise the delicate balancing required. While avoiding issues around eligibility criteria, it underscores the point that SDT should be "needs-driven and evidence-based" effectively, targeting more differentiation amongst countries, available at http://trade.ec.europa.eu/ doclib/docs/2018/september/tradoc_157331.pdf (accessed 10 August 2020).

26. Contrastingly, this approach does not focus on country categorisation. It is rather agreementspecific. For an earlier exposition of this approach, (Hoekman et al., 2003; Keck and Low, 2004; and Stevens, 2002).

27. WTO (2007), WTO Analytical Index: Guide to WTO Law and Practice, Vol. 1, p. 90, Cambridge University Press, Cambridge, UK. See also WTO (2012), WTO Analytical Index: Guide to WTO Law and Practice, ( $3^{\text {rd }}$ Edition), Cambridge University Press, Cambridge, UK.

28. Using the TRIPS Agreement, Gonzalez et al. (2011) identified four possible constraints (economic constraints, access to pharmaceuticals, capacity constraints and incidence of health outcomes) that make developing countries particularly vulnerable to patent protection enforcement, on which basis they then selected relevant indicators that capture these constraints. Further basing on a combination of the indicators, they were able to draw up a list of countries that were deserving of exemption from TRIPS provisions for patent protection in the pharmaceutical industry.

29. See Article XXV of GATS, Article 11 of the TBT Agreement, Article 9 of the SPS Agreement, Article 67 of the TRIPS Agreement.

30. The Montreal Protocol on Substances that Deplete the Ozone Layer (the Montreal Protocol) is an international agreement made in 1987. It was designed to stop the production and import of ozone-depleting substances and reduce their concentration in the atmosphere to help protect the earth's ozone layer.

31. At the time of the making of the Montreal Protocol, China was the largest producer and consumer of chlorofluorocarbons (CFCs). However; it recorded tremendous success in implementing a national plan for the phasing-out of ODS, implemented scores of domestic policies and regulations to control the production, consumption, import and export of ODS and remarkably, shut down all its production plants for CFCs well ahead of the schedule set by the Montreal Protocol. All because of the establishment of a Multilateral Fund under the Protocol to support developing countries meet their ODS reduction target, with funding linked to achieving compliance and sustainable ODS reduction and a requirement of a data reporting system as pre-condition for accessing the Fund.

32. Under Article XVI (4) of Agreement Establishing the WTO, developing countries were given five years from the entry into force of the Agreement to review their local laws to conform to provisions of the covered agreements.

33. WTO, Doha Work Programme (the July Package), General Council Decision of 1 August 2004, WT/L/535, available at https:/www.wto.org/english/tratop_e/dda_e/ddadraft_31jul04_e.pdf (accessed 7 July 2020).

34. Ibid, at Article 48.

35. WTO (2019a), “An Undifferentiated WTO: self-declared Development Status Risk Institutional Irrelevance", Communication from the United States WT/GC/W/757, WTO, Geneva, 16 January).

36. European Commission (2018), "WTO Modernisation: Introduction to Future EU Proposals", European Union Concept Paper, Brussels, 18 September, available at: https:/ec.europa.eu/ commission/presscorner/detail/en/IP_18_5786 (accessed 24 January 2021). 
37. WTO (2019c), "Pursuing the Development Dimension in WTO Rule-Making Efforts", Communication from Norway, Canada, Hong Kong, China, Iceland, Mexico, New Zealand, Singapore and Switzerland, WT/GC/W/770/Rev.3, WTO, Geneva, 7 May.

38. WTO (2018), "Strengthening and Modernizing the WTO: Discussion Paper", Communication from Canada”, JOB/GC/201, WTO, Geneva, 24 September.

\section{References}

Bacchus, J. (2004), Trade and Freedom, London: CMP Publishing,

Bacchus, J. and Manak, I. (2020), "The development dimension: what to do about differential treatment in trade", Policy Analysis No. 887, Cato Institute, 13 April, available at www.cato.org/ publications/policy-analysis/development-dimension-what-do-about-differential-treatment-trade (accessed 12 June 2020).

Chang, H. (2002), Kicking Away the Ladder: Development Strategy in Historical Perspective, Anthem Press, London.

Conconi, P. and Perroni, C. (2015), "Special and differential treatment of developing countries in the WTO”, World Trade Review, Vol. 14 No. 1, pp. 67-86.

Cottier, T. (2006), "From progressive liberalisation to progressive regulation in WTO law", Journal of International Economic Law, Vol. 9 Issue No. 4, pp. 779-821 at 792.

Cui, F. (2008), "Who are the developing countries in the WTO?", The Law and Development Review, Vol. 1 Issue No. 1, pp. 121-152, at 133.

European Commission (2018), "WTO Modernisation: Introduction to Future EU Proposals", European Union Concept Paper, Brussels, 18 September, available at: https:/ec.europa.eu/commission/ presscorner/detail/en/IP_18_5786 (accessed 24 January 2021).

Finger, M. (1991), "Development economics and the general agreement on tariffs and trade", in De Melo, J. and Sapir, A. (Eds), Trade Theory and Economic Reform: North, South, and East: Essays in Honour of Bela Balassa, Cambridge, MA.

Francois, J., et al. (2006), "Preference erosion and multilateral liberalization", The World Bank Economic Review, Vol. 20 No. 2, pp. 197-216.

Gonzalez, J.L., Parra, M.M., Holmes, P. and Shingal, A. (2011a), "TRIPS and Special and Differential Treatment - Revisiting the Case for Derogations in Applying Patent Protection for Pharmaceuticals in Developing Countries", Working Paper No. 2011/37, National Centre of Competence in Research, Berne, Switzerland, May.

Gonzalez, J.L., Parra, M.M. and Holmes, P. (2011), "Towards a new age in special and differential treat", Working Paper No. 2011/58, National Centre of Competence in Research, Berne, Switzerland, May.

Hoekman, B. (2005), "Operationalizing the concept of policy space in the WTO: beyond special and differential treatment", Journal of International Economic Law, Vol. 8 No. 2, pp. 405-424 at 412 .

Hoekman, B., et al. (2003), "More favourable and differential treatment of developing countries: towards a new approach in the WTO", Policy Research Paper 3107, the World Bank, Washington, DC, available at: http://elibrary.worldbank.org/doi/pdf/10.1596/1813-9450-3107 (accessed 8 February 2020).

Hoekman, B., et al. (2004), "Special and differential treatment of developing countries in the WTO: moving forward after Cancun", The World Economy, Vol. 27 No. 4, pp. 481-506 at 490.

Imboden, N. (2017), "Special and differential treatment: a new approach may be required", Bridges Africa, Vol. 6 No. 8.

Keck, A. and Low, P. (2004), "Special and differential treatment in the WTO: Why, when and how?", Staff Working Paper ERSD-2004-03, WTO, Geneva. 
JITLP 20,2

Kleen, P. and Page, S. (2005), "Special and differential treatment of developing countries in the world trade organization", Global Development Studies No. 2, available at: www.odi.org/sites/odi.org. uk/files/odi-assets/publications-opinion-files/3320.pdf (accessed 6 February 2020).

Lee, Y. (2016), "The long and winding road - path towards facilitation of development in the WTO: reflections on the Doha round and beyond", Law and Development Review, Vol. 9 Issue No. 2, pp. 437-456 at 448.

Low, P., Mamdouh, H. and Rogerson, E. (2019), Balancing Rights and Obligations in the WTO - a Shared Responsibility, p. 27. Geneva: IDEAS Centre.

Mandelson, P. (2005), "Doha for Development", Speech to Informal Meeting of EU Development Ministers, Leeds, UK, available at: https://ec.europa.eu/commission/presscorner/detail/en/SPEECH_05_639 (accessed 8February 2020).

Ornelas, E. (2016), "Special and differential treatment for developing countries", Discussion Paper No 1415, Centre for Economic Performance, London School of Economics and Political Science, London, available at: http://cep.lse.ac.uk/pubs/download/dp1415.pdf (accessed 6 February 2020).

Page, S. (2004), "The evolution of special and differential treatment in the multilateral trading system", paper presented at International Centre for Sustainable Development (ICTSD) workshop, 6 December 2004, Geneva, available at: www.odi.org/sites/odi.org.uk/files/odi-assets/publicationsopinion-files/4679.pdf (accessed 7 June 2020).

Paugam, J. and Novel, A. (2005), "Why and how differentiate developing countries in the WTO? Theoretical options and negotiating solutions", paper presented at Ifri/AFD Conference 28 October 2005, Paris, available at: www.ifri.org/sites/default/files/atoms/files/novel_paugam_nov_2005.pdf (accessed 9 August 2020).

Prowse, S. (2002), "The role of international and national agencies in trtade-related capacity building", The World Economy, Vol. 25 No. 9, pp. 1235-1261.

Rolland, S. (2012), Development at the WTO, p. 80, Oxford University Press. Oxford.

Rolland, S.E. (2012), "Considering development in the implementation of panel and appellate body reports", Trade, Law and Development, Vol. 4 No. 1, pp. 150-199.

Sen, A. (1999), Development as Freedom, Random House, New York, NY.

Shafaeddin, M. (1998), "How did developed countries industrialize? The history of trade and industrial policy: the case of Great Britain and the USA", Discussion Paper No. 139, UNCTAD, Geneva, December.

Stevens, C. (2002), "The future of special and differential treatment (SDT) for developing countries in the WTO”, Working Paper No. 163, 1 January, Institute of Development Studies, Sussex England, available at: www.ids.ac.uk/publications/the-future-of-special-and-differential-treatment-sdt-fordeveloping-countries-in-the-wto/ (accessed 9 August 2020).

Surono, A. and Hidayati, M. (2019), "Special and differential treatment in the WTO agreement on agriculture and the benefits for developing countries", Academic Journal of Interdisciplinary Studies, Vol. 8 No. 4, pp. 132-139.

UNCTAD (2019), Key Statistics and Trends in International Trade 2018, UNCTAD, Geneva.

USG (2019), "Reforming developing-country status in the world trade organization", Federal Register, Vol. 84 No. 147, pp. 37555-37557. available at: www.govinfo.gov/content/pkg/FR-2019-07-31/pdf/ 2019-16497.pdf (accessed 6 July 2020).

Verdirame, G. (1996), "The definition of developing countries under GATT and other international law", German Year Book of International Law, Vol. 39, pp. 164-197.

Verter, N. (2017), "International trade: the position of Africa in global merchandise trade", in Ibrahim, M. (Ed.), Emerging Issues in Economics and Development, IntechOpen, London, pp. 65-89.

World Street Journal (2004), "Robert Zoellick's Letter to WTO Member Nations", available at: https:// www.wsj.com/articles/SB107393275634376900 (accessed 7 August 2020). 
WTO (2001), "Preparations for the fourth session of the ministerial conference: proposal for a framework agreement on special and differential treatment, Para. 1, WT/GC/W/442, 19 September".

WTO (2019a), "An undifferentiated WTO: self-declared development status risk institutional irrelevance", Communication from the United States WT/GC/W/757, WTO, Geneva, 16 January.

WTO (2019b), "The continued relevance of special and differential treatment in favour of developing members to promote development and ensure inclusiveness", Communication from China, India, South Africa and the Bolivarian Republic of Venezuela WT/GC/W/765, WTO, Geneva, 28 February.

WTO (2019c), "Pursuing the development dimension in WTO rule-making efforts", Communication from Norway, Canada, Hong Kong, China, Iceland, Mexico, New Zealand, Singapore, and Switzerland, WT/GC/W/770/Rev.3, WTO, Geneva, 7 May.

WTO (2018), "Strengthening and Modernizing the WTO: discussion Paper", Communication from Canada, JOB/GC/201, WTO, Geneva, 24 September.

WTO (2012), "WTO Analytical Index: Guide to WTO Law and Practice", (3rd Edition), Cambridge University Press, Cambridge, UK.

WTO (2007), "WTO analytical index: guide to WTO law and practice", Cambridge University Press, Cambridge, UK, Vol. 1, p. 90.

\section{Further Reading}

Alavi, A. (2007), "On the (non-)effectiveness of the world trade organization special and differential treatments in the dispute settlement process", Journal of World Trade, Vol. 41 No. 2, pp. 319-349.

Christie, A. (2009), "Special and differential treatment in the GATT: a pyrrhic victory for developing countries", The Estey Centre Journal of International Law and Trade Policy, Vol. 10 No. 2, pp. 63-84.

Ezeani, E. (2013), "WTO post Doha: trade deadlocks and protectionism”, Journal of International Trade Law and Policy, Vol. 12 No. 3, pp. 272-288.

Fukasaki, K. (2000), "Special and differential treatment for developing countries: does it help those who help themselves?”, UNU World Institute for Development Economics Research. Wider Working Paper No. 197. Helsinki, Finland, available at: www.docsonline.wto.org (accessed 6 July 2020).

Hoeckman, B., Michalopoulos, C. and Winters, L.A. (2003), "Special and differential treatment in the WTO after Cancun”, The World Economy, Vol. 27 No. 4, pp. 481-506.

Hoff, K. and Stiglitz, J.E. (2000), "Modern economic theory and development", in Meier, G.M. and Stiglitz, J.E. (Eds), Frontiers of Development Economics: The Future in Perspective, (pp. 389-459). Oxford: World Bank and Oxford University Press.

Jackson, J.H. (1989), The World Trading System, Cambridge: MIT Press.

Kerr, W.A. (2005), "Special and differential treatment: a mechanism to promote development?", Estey Centre Journal of International Law and Trade Policy, Vol. 6 No. 2, pp. 84-94.

Kessie, E. (2000b), "Enforceability of the legal provisions relating to special and differential treatment under the WTO agreements", The Journal of World Intellectual Property, Vol. 3 No. 6, pp. 955-975.

Mangeni, F. (2003), Strengthening Special and Differential Treatment in the WTO Agreements: Some Reflections on the Stakes for African Countries, International Centre for Trade and Sustainable Development (ICTSD).

Michalopoulos, C. (2000), "The role of special and differential treatment for developing countries in GATT and the world trade organization”, World Bank, Policy Research Working Paper 2388, 1, available at: https://openknowledge.worldbank.org/handle/10986/19819 (accessed 6 July 2020). 
JITLP

20,2

100

OECD (2008), "Handbook on constructing composite indicators: methodology and user guide", available at: www.oecd.org/publishing

Prévost, D. (2005), “Operationalising special and differential treatment of developing countries under the SPS agreement”, South African Yearbook of International Law, Vol. 30, pp. 1-31.

Senona, J.M. (2008), "Negotiating special and differential treatment from Doha to post-Hong Kong: Can poor people still benefit?”, Journal of World Trade, Vol. 42 No. 6, pp. 1041-1064.

Subedi, S.P. (2006), "The notion of free trade and the first ten years of the world trade organisation: How level is the 'level playing fields?"', Netherlands International Law Review, Vol. 53 No. 2, pp. 273-296.

Switzer, S. (2017), “A contract theory approach to special and differential treatment and the WTO”, Journal of International Trade Law and Policy, Vol. 16 No. 3, pp. 126-140.

Verwey, D. (1983), “The principle of preferential treatment for developing countries”, Indian Journal of International Law, Vol. 23, pp. 36-48.

Whalley, J. (1999), "Special and differential treatment in the millennium round", Center for the Study of Globalisation and Regionalisation. Working Paper 30/99, available at http://wrap.warwick.ac. uk/2095/ (accessed 14 July 2020).

Corresponding author

Aniekan Ukpe can be contacted at: aniekan.ukpe@gmail.com

For instructions on how to order reprints of this article, please visit our website: www.emeraldgrouppublishing.com/licensing/reprints.htm

Or contact us for further details: permissions@emeraldinsight.com 